\title{
Virtual character personality influences participant attitudes and behavior - an interview with a virtual human character about her social anxiety
}

\author{
Xueni Pan ${ }^{1}$, Marco Gillies ${ }^{2}$ and Mel Slater ${ }^{1,3}$ * \\ 1 Department of Computer Science, University College London, London, UK \\ ${ }^{2}$ Department of Computing, Goldsmith, University of London, London, UK \\ ${ }^{3}$ EVENT Lab, Facultat de Psicologia, ICREA-Universitat de Barcelona, Barcelona, Spain
}

\section{Edited by:}

Ming C. Lin, University of North

Carolina at Chapel Hill, USA

\section{Reviewed by:}

Kyle John Johnsen, University of Georgia, USA

Benjamin Lok, University of Florida USA

Sujeong Kim, University of North Carolina at Chapel Hill, USA

*Correspondence:

Mel Slater, Event Lab, Facultat de Psicologia, Universitat de Barcelona, Campus de Mundet-Edifici Teatre, Passeig de la Vall d'Hebron, 171, Barcelona 08035, Spain

e-mail:melslater@ub.edu
We introduce a novel technique for the study of human-virtual character interaction in immersive virtual reality. The human participants verbally administered a standard questionnaire about social anxiety to a virtual female character, which responded to each question through speech and body movements. The purpose was to study the extent to which participants responded differently to characters that exhibited different personalities, even though the verbal content of their answers was always the same. A separate online study provided evidence that our intention to create two different personality types had been successful. In the main between-groups experiment that utilized a Cave system there were 24 male participants, where 12 interacted with a female virtual character portrayed to exhibit shyness and the remaining 12 with an identical but more confident virtual character. Our results indicate that although the content of the verbal responses of both virtual characters was the same, participants showed different subjective and behavioral responses to the two different personalities. In particular participants evaluated the shy character more positively, for example, expressing willingness to spend more time with her. Participants evaluated the confident character more negatively and waited for a significantly longer time to call her back after she had left the scene in order to answer a telephone call. The method whereby participants interviewed the virtual character allowed naturalistic conversation while avoiding the necessity of speech processing and generation, and natural language understanding. It is therefore a useful method for the study of the impact of virtual character personality on participant responses.

Keywords: personality, virtual human, social anxiety, virtual reality, character

\section{INTRODUCTION}

Participants in an immersive virtual reality (IVR) can interact with proximal life-sized virtual human characters, which can talk with them, look them in the eye, smile, walk around, move into their space - with the possibilities only limited by the capabilities of the programing and system. What is surprising is that people tend to respond realistically in these virtual social interactions in spite of the often quite simplistic nature of the visual and behavioral representations of the characters portrayed. For example, in our own earlier work we have found that participants become stressed when giving a talk to a virtual audience that displays negative behaviors toward the speaker but not when the audience behaves positively (Pertaub et al., 2002), and generally they are more likely to respond realistically to virtual human characters when these are more responsive to them (Garau et al., 2005). In an IVR reprise of one of the conditions of Stanley Milgram's Obedience to Authority experiments (Milgram, 1974), volunteers displayed signs of stress and anxiety on giving "electric shocks" to a female virtual human character whenever she answered a question incorrectly (Slater et al., 2006). Men responded differently to the approach of a virtual woman at a party depending on whether they were shy or confident in interactions with women in real life (Pan et al., 2012). In each of these studies quite crude looking virtual humans were displayed, but they nevertheless evoked clear affective responses in participants. More realistic looking virtual humans, though still cartoon-like, were used in the study described in Slater et al. (2013), where male participants witnessed aggression by one virtual male character on another due to opposing soccer club affiliations. It was found that when the victim and participant were both fans of the same soccer club (the one derided by the aggressor) then the participant was more likely to intervene to try to stop the fight. This tendency was enhanced if the participant believed that the victim was sometimes looking toward him for help.

Bailenson et al. (2005) observed in IVR the behavior of participants when being asked to approach virtual agents with humanlike or random head movements. The result suggested that they showed greater hesitation in approaching the agent with more human-like movements. Vinayagamoorthy et al. (2008) found that participants tended to adopt socially acceptable spatial behavior with virtual characters that displayed emotions. Pan et al. (2008) observed the bodily movements of male participants during an interaction with a female virtual character, and results showed 
that participants' head movements indicated a higher level of involvement as the interaction progressed.

An experiment was reported in Zanbaka et al. (2007) where participants were inhibited by the presence of others when performing a task, whether those others were virtual or real humans. Other classic results from social psychology have also been found to hold within IVR, such as proxemics (Bailenson et al., 2003; Llobera et al., 2010; Kastanis and Slater, 2012). As a result IVR has been proposed and exploited as a medium for social psychological research by many different research groups (Loomis et al., 1999; Blascovich, 2002; Blascovich et al., 2002; Gillath et al., 2008; McCall et al., 2009; Rovira et al., 2009). Moreover, the success of IVR in being able to portray social interactions is also demonstrated by its utility in psychological therapy (Hodges et al., 2001; Emmelkamp et al., 2002; Anderson et al., 2003; Krijn et al., 2004; Rizzo and Kim, 2005; Cukor et al., 2009): if it did not produce appropriate affect in therapy clients, then it would not be useful.

Enhancing interactions between people and virtual human characters, so that these become similar to human-human social interaction, has been addressed in the literature, mainly concerned with methods to generate convincing behavior. Vinayagamoorthy et al. (2006) argued that the character has to adopt a credible form in both appearance and movements. Furthermore, the character should afford feedback to the participant though eye gaze (Lee et al., 2002; Garau et al., 2003; Vinayagamoorthy et al., 2004), proxemics (Bailenson et al., 2003), or real-time language responses such as appropriate listening behavior - e.g., Maatman et al. (2005). In this work, however, we do not consider the question of how to generate appropriate behavior, but rather the personality context in which the behavior occurs.

We focused on social anxiety as the personality trait of interest since it is easily recognized (Connelly and Ones, 2010), and relates to our previous work (Pan et al., 2012). We describe an experiment that examined how people respond toward two different personalities that we label as "shy" and socially "confident." The "shy" virtual character was designed to display social anxiety, and the "confident" character to be socially confident, but which was also interpreted as aggressive, disagreeable, or inconsistent. Hence, we use "shy" and "confident" only as labels for two different personality types at approximate opposite poles on a social anxiety dimension, but also involving other attributes of personality such as disagreeableness. In both conditions, the female virtual character displayed no changes in facial expressions and gave exactly the same verbal responses in the interaction. Her personality was expressed through body movements and tone of voice.

The scenario, described in more detail in the next sections, involved male participants interviewing a female virtual character, administering a questionnaire about social anxiety to her. The character was displayed in a four walled projection system of the generic type commonly referred to as a "Cave" (Cruz-Neira et al., 1992). Although the character gave answers to the questionnaire that indicated a high level of social anxiety, in one condition her body language and tone of voice expressed "shyness" and in the second condition "confidence." After the interview, the character left the room but said that she would return shortly - although she never did. Our first hypothesis was that participants would subjectively evaluate the confident character with more negative attributes than the shy character. Our second hypothesis was that the waiting times of participants before they called the character to return, or terminated the experiment themselves, would be influenced by the character's personality type, where they would be more reluctant to recall the more disagreeable character.

\section{MATERIALS AND METHODS IMPLEMENTATION OF THE PERSONALITY TYPES}

The expressions of shyness and embarrassment include blushing, nervous smile, face touches, adverted gaze, more speech disturbances, more bodily motion, and stiff posture (Edelmann and Hampson, 1981; Coll et al., 1984; Asendorpf, 1990; Keltner and Buswell, 1997). Paul (1966) developed a Timed Behavioral Checklist for Performance Anxiety (TBCL), which consists of 20 features associated with social anxiety. We categorized those features into behaviors related to six different parts of the body, and ranked these by the number of Items in each one as shown in Table 1. We used motion capture in order to animate the virtual characters using two out of the six categories, bodily movement and voice and speech, accounting for 13 out of 20 features in Table 1.

The motion capture sessions were with a professional actor, who read our script in advance of the motion capture session. Upon arriving, we instructed her regarding the technical details and the purpose of the experiment, and she rehearsed the script in front of a volunteer. We carried out the motion capture with a Vicon motion capture system. Thirty-two markers were used to capture her movements. During the capture for the first condition, she was told to act as if she were very shy and anxious. As shown in Figure 1A, she kept her head low a relatively stiff overall body posture but with frequent movements. In contrast, she was instructed to behave somewhat confidently and aggressively, sometimes leaning forward to the interviewer, in the control condition (Figure 1B). Her voice was recorded at the same time as the motion capture procedure.

The motion-captured animation was created with 3DS Max and a female virtual character from Poser was used. The pipeline was as follows: (i) a female virtual character, originally created

Table 1 | Behaviors related to high level of social anxiety categorized by different parts of the body.

\begin{tabular}{lll}
\hline Category & Behaviors & No. of items
\end{tabular}

Bodily Paces, sways, shuffles feet, knees tremble,

movements extraneous arm and hand movement, hand tremors, arms rigid, and hands restrained

Voice and Swallows, clears throat, breaths heavily, speech voice quivers, speech blocks, or stammers Facial Face muscles tense, face "deadpan," 3 expressions moistens lips Facial Blushing, face pale 2

colors

Gaze No eye contact $\quad 1$

Other Perspires 1

Based on the TBCL. 


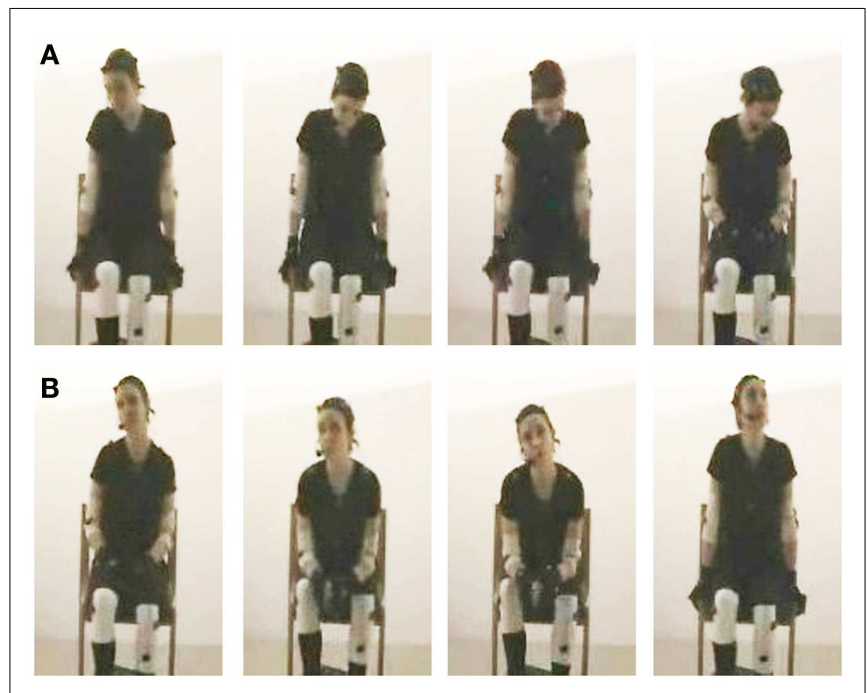

FIGURE 1 |The actor showing various poses for the motion capture (A) Shy condition and (B) confident condition.

using Poser, was exported with chosen clothing and hair style, to 3DS Max with the Gesture Max plugin. (ii) Rigging (linking the character mesh and the biped skeleton) was performed in 3DS Max, which defined the link between the imported mesh and the biped (provided by 3DS Max). (iii) The motion-captured data were applied on to the rigged character. (iv) The animation was adjusted by hand to remove intersections (the character's hands or fingers occasionally intersecting its body). This was done by adding another layer of animation in 3Ds Max.

The scenario was implemented using Platform Independent API for Virtual Characters and Virtual characters (PIAVCA) (Gillies and Spanlang, 2010) and XVR (Tecchia et al., 2010). The virtual character followed a pre-defined script and interacted with the participants in real-time. For each utterance in the script we constructed an event in the experiment timeline that contained both voice and synchronized body animation. During the experiment, all events were displayed on a control panel, and real-time interaction was achieved through the triggering of appropriate response events from this control panel by a remote operator who was listening to the interaction. A similar set up was used in our previous study (Pan et al., 2012).

\section{VR EQUIPMENT}

The experiment was conducted in a Cave-like projection based system that has three back-projected vertical screens (front, left, and right) $(3 \mathrm{~m} \times 2.2 \mathrm{~m})$ and a floor screen (from a ceiling mounted projector) $(3 \mathrm{~m} \times 3 \mathrm{~m})$ controlled by a five-node cluster. The back of the Cave system is open but a heavy black curtain was closed during the experiment to prevent the participant from being too aware of the experimenters. As shown in Figure 2, the participants wore 3D stereo glasses (Crystal Eyes, Stereographics), which are shutter glasses in sync with the screen displays, refreshed at $45 \mathrm{~Hz}$ for each eye. The fusion of left and right images creates a stereo view. The participants also wore a head-tracker (Intersense 900) that tracks the position and orientation of the head so that the

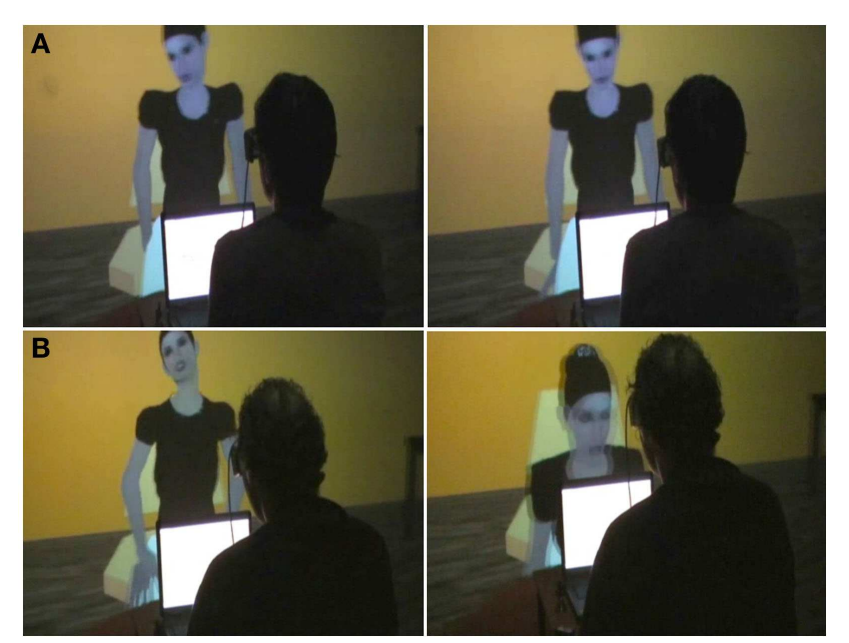

FIGURE 2 | Showing a participant interacting with the virtual character. (A) Shy condition, (B) confident condition. The images are blurred since this was photographed directly from the Cave screens, which display in 3D, and therefore with double images.

computer refreshes the displays according to head orientation and position, thus allowing the creation of head-movement parallax.

\section{EXPERIMENTAL DESIGN AND RECRUITMENT}

This was a between-groups experiment where each participant experienced only one type of virtual character. Twenty-four male participants were recruited through emails around University College London (UCL) and also from the UCL Psychology Subject Pool. The age range was 20-35 years for all but one who was 62 (who did not show up as an outlier in analysis). All participants were fluent in English. The study was approved by the UCL Research Ethics Committee. There were therefore 12 participants in each of the Shy and Confident conditions.

\section{PROCEDURES AND SCENARIO}

Participants attended the experiment at pre-arranged times, and were assigned to the experimental conditions in the order that they came (i.e., first one Shy, second Confident, and so on). On arrival participants were given an information sheet, and ethics forms, with written informed consent, and advised that they were free to withdraw from the experiment at any time without giving reasons. The experimenter then gave them a computer-based pre-questionnaire asking information such as age, occupation, etc. They were given some pre-experiment questionnaires to complete including a questionnaire on Social Avoidance and Distress Scale (SAD) and the NEO Personality Inventory (described below).

The participant was told both in writing and verbally that we were going to test certain aspects of our Virtual Reality system, and the task was to interview a virtual human, following a set script. The interview scenario was chosen since it is often an encounter that triggers social anxiety. Furthermore, the technical advantage was that using this format we could control what the participants would say - since they were given interview questions that they had to ask the virtual interviewee in a given order. This had the further 
advantage that we could pre-record the answers given by the virtual interviewee, and thus avoid all problems of speech recognition, and yet still have a quite sophisticated and realistic conversation between the participant and the virtual character. Additionally, participants were told that this was part of a training exercise for the conduct of interviews, so that the setup could be plausible. They were also told that during the interview it would be important to look at the interviewee after reading out the question and while waiting for her answer.

Then the participants put on stereo glasses and entered the Cave. Inside the Cave space they were seated in front of a physical table on which there was a laptop and a small bell. Then the experimenter again explained that their task was to carry out an interview, and demonstrated to the participants how all of the instructions and all of the interview questions could be seen on the laptop on the desk at which they were seated. After finally checking that everything was understood, the experimenter left the participants in the Cave by themselves.

After waiting in the scenario for $2 \mathrm{~min}$, the participant heard some noises played from outside the Cave. These consisted of a pre-recorded conversation between a male authority figure and a female, who apparently was reluctant to enter the room. Eventually the female was heard to agree to attend the interview (Supplementary Material 1.1).

The female virtual character, which we refer to as "Jenny," then walked into the scenario, and sat on the other side of the table (Figure 2; Videos S1,S2 in Supplementary Material). After an introduction, the participant started to read out loud the instructions from the laptop to Jenny (an example from a typical conversation is given in Supplementary Material 1.2). This was followed by the participant reading out questions displayed on the laptop in front of him. The participant would already have been familiar with the questions since they were exactly the same as one of the questionnaires (SAD) that he had completed earlier. The difference was that instead of the questions referring to himself (e.g., "I try to avoid formal social occasions"), they referred to the interviewee ("You try to avoid formal social occasions"). Hence each question was a statement to which the interviewee could agree or disagree. Every time the participant read out such a statement he looked at the virtual character and waited for her to respond. The instructions required her to answer "I agree" or "I disagree." After she responded he then had to enter her answer into a form displayed on the laptop in order to proceed to the next question. The virtual character answered every question, sometimes after a small pause, and sometimes she acted as if she was having problems answering the question, often embellishing her answers with additional statements such as "I suppose ...." Sometimes she made additional comments such as "This is a bit embarrassing isn't it?", and sometimes she asked the participant to repeat the question (Supplementary Material 1.3).

During the interaction the virtual character behaved either shyly (Figure 2A; Video S1 in Supplementary Material), displaying a closed posture with her head lowered down or confidently (Figure 2B; Video S2 in Supplementary Material), displaying a more dominant posture by expanding her body, raising her head, and leaning toward the participant. The whole experience was recorded with a video camera from behind the participants. In both conditions (shy and confident) the virtual character gave the same answers to every question, answers that implied that she was very shy (i.e., the "confident" Jenny answered the questions with answers that suggested social anxiety - even though she answered in a more forthright and confident manner than the "shy" Jenny). Leary (1983) (p. 67) referring to Snyder (1974) reports that some socially anxious people "... may not display overt signs of their inner distress and are able to hide their anxiety behind a cloak of false composure." Moreover, Leary uses Zimbardo's term "shy extroverts" (Henderson et al., 2010) noting that such people "... have learned the appropriate social behaviors necessary for effective interaction and have developed the ability to conceal the indices of privately experienced anxiety." Hence our "confident" virtual character expressing social anxiety in answering to the questionnaire over a façade of more forthright behavior is a type of personality known in the literature.

The interview lasted between 5 and 10 min depending on the speed of the participant reading the statements. When it was completed the virtual character showed relief and asked if the participant could do her a favor in return. She then asked the participant himself to complete another questionnaire now displayed on the laptop in front of him, and told him that she and he would review his answers together later.

The participant began answering the questions (by choosing options on the laptop screen). These questions were an evaluation of the virtual character herself (for example, whether the participant would like to meet her again; whether he found her likable, reliable, or trustworthy, etc.). Just before he was ready to answer the questionnaire a telephone from outside the Cave started ringing. Jenny then apologized and told the participant that she had to leave to answer the phone. She pointed to a small bell on the participant's desk and told him to ring it to call her when he had finished the questionnaire, and then she stood up and quickly walked out. The participant would at first have been able to hear her picking up the phone and talking quietly in the background, but eventually she could no longer be heard.

The participant was left alone in the scenario depicted in the Cave to finish the questionnaire, and after he finished the questionnaire he rang the bell. However, the virtual character never returned. Every participant always rang the bell again after waiting some time. However, she still did not return. He might ring the bell again, and again, until deciding to give up. The experiment was terminated when the participant decided to stop and left the Cave, or if he started calling the experimenter. The cut-off time for termination was $10 \mathrm{~min}$ after the character (Jenny) walked out. Hence if after this time the participant had not already stopped, the experimenter opened the Cave curtain, apologized to him, and explained that the virtual character would not return to the scenario.

After the experiment, participants were given a presence questionnaire and a short interview. Finally in a debriefing session, the experimenter explained to the participants the design and the actual purpose of the experiment. They were paid 10 pounds (UK).

\section{RESPONSE AND EXPLANATORY VARIABLES}

Before the experiment, the participant was required to complete a pre-questionnaire: SAD (Watson and Friend, 1969), which 
included 27 statements associated with social anxiety, which he could choose either to "agree" or "disagree." As an example, the following are three questions from the questionnaire:

1. I usually feel relaxed when I meet someone for the first time.

2. I try to avoid formal social occasions.

3. I often feel on edge when I talk to a group of people.

The overall score was the sum of answers that reflected the participant's social anxiety level. For example, choosing "disagree" for statement (1) and "agree" to statement (2) and (3) would each add 1 to the SAD score.

Participants also answered a standard personality questionnaire: the NEO big-five factor (McCrae and Costa, 1999), which characterizes extroversion, agreeableness, conscientiousness, neuroticism, and openness.

The response variables in which we were interested were: (1) how long participants would wait before ringing the bell for a second time (second bell time); (2) how long they would wait until terminating the experiment (end time). Our focus is whether these times depended on the personality of the virtual character.

As mentioned above, before the virtual character left the Cave she had told the participants to complete a questionnaire where they have to give their opinion about her (for example, whether he found her likable), the result of which was used as another measurement. Moreover, we used a questionnaire to assess participants' level of presence in both conditions (Slater and Steed, 2000).

\section{VALIDATION OF THE REPRESENTATION OF PERSONALITY THROUGH AN ONLINE STUDY}

In order to obtain an independent evaluation of the two personalities we created, a separate online study was conducted with participants who viewed the video of interaction and were then asked to rate the personality of the virtual character. During pilot runs of experiment we captured videos of the interaction from behind the participant (facing the virtual character, as demonstrated in Figure 2). We selected two videos (one from each condition) and let another group of people judge the personality of the virtual character based on the videos. We advertised the links to the online study through the UCL psychology subject pool, as well as through social media. Participants were randomly assigned to view either Shy or Confident video conditions, after which they were directed to a questionnaire to evaluate the personality of the virtual character. Here, a single-item measures of personality (SIMP) questionnaire was used (Woods and Hampson, 2005).

Overall, 45 participants completed the questionnaire (22 watched the video of the "shy" virtual character, 10 of which were male, and 23 the "confident" virtual character video, 11 were male). The boxplots of the five dimensions of the personalities for each condition is shown in Figure 3. It is clear from the boxplots that the two conditions differ on the personal traits of Introversion (Wilcoxon rand-sum test $P=0.0009$ ), Agreeableness (Wilcoxon rand-sum test $P=0.015$ ), and Openness (Wilcoxon rand-sum test $P=0.006)$. This shows that in the Shy condition the virtual character appeared to be more introverted, more agreeable, and

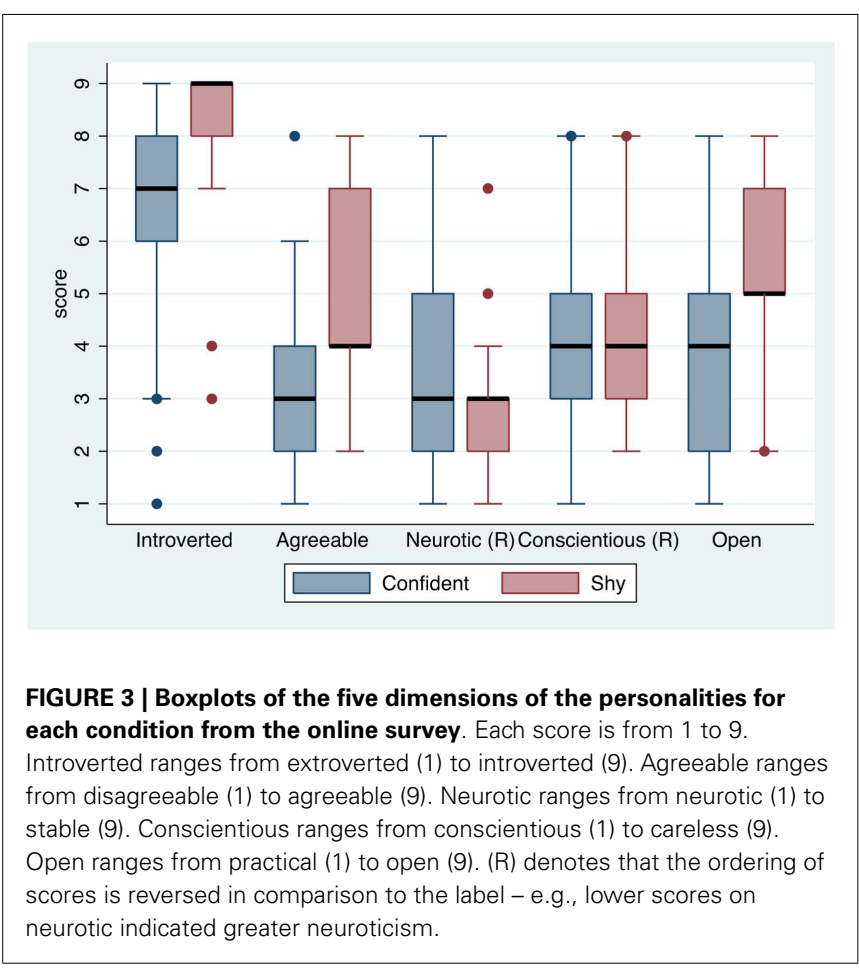

Table 2 | Mean (SD) of the NEO personality variables, SAD questionnaire scores, and age by experimental group ( $n=12$ each group)

\begin{tabular}{lcr}
\hline Variable & Confident & Shy \\
\hline Neuroticism & $22.7(8.3)$ & $20.2(9.0)$ \\
Extraversion & $29.1(6.0)$ & $27.0(4.9)$ \\
Openness & $33.7(6.0)$ & $28.7(6.7)$ \\
Agreeableness & $30.8(6.8)$ & $29.4(5.2)$ \\
Conscientiousness & $31.4(6.4)$ & $28.3(4.9)$ \\
SAD & $8.8(6.9)$ & $5.5(5.5)$ \\
Age & $29.4(10.6)$ & $24.6(4.3)$ \\
\hline
\end{tabular}

more open, compared to the Confident condition. These differences therefore provide a more precise meaning of the labels "Shy" and "Confident" used throughout this paper.

\section{RESULTS}

\section{PARTICIPANTS' AGE AND PERSONALITY}

Table 2 shows comparisons of the two experimental groups by age and the NEO personality test results. Inspection shows no obvious important differences between the two groups. To test this, while limiting the number of significance tests, we carried out a MANOVA to test the hypothesis that the mean vectors are equal for both groups. The Doornik-Hansen test of multivariate normality separately for the two groups shows that each is compatible with multivariate normality ( $P=0.10$ for the confident and $P=0.64$ for the shy group). The MANOVA does not reject the hypothesis of equal mean vectors ( $P=0.26$, Wilks' Lambda). 


\section{REACTIONS TO THE SHY AND CONFIDENT CHARACTERS}

Prior to the virtual character Jenny leaving the Cave she had asked the participants to complete the questionnaire about herself, which she told them she would later review together with them.

There were eight statements that required yes/no answers on this questionnaire regarding the participant's general feelings toward the character, where "yes" responses indicated a more favorable feeling toward her. The statements and responses are shown in Table 3.

We take as the overall response variable the proportion of "yes" answers, with means and standard errors shown in Table 3. A $t$-test for the difference between the means results in $|t|=2.42, P=0.024$, two-sided, Cohen's $d=0.99$. A nonparametric Wilcoxon rank-sum test results in $|z|=2.14, P=0.03$. From an inspection of the proportions in Table 3, the evidence suggests that overall the character in the Shy condition was evaluated more favorably than the one in the Confident condition. This questionnaire was designed to use the mean of the responses (which is why only binary answers were chosen) but for interest we also show the $P$ values for the tests of differences between the proportions in each group.

To further demonstrate that the answers to these questions reliably discriminate between the two groups we carried out a canonical linear discriminant analysis (using the Stata 13 function "candisc"). Amongst those in the Shy condition the discriminant function classified 11 as shy and 1 as confident. Amongst those in the Confident group it classified 9 as confident and 3 as shy. Hence these variables alone can quite well discriminate between the two groups. Inspection of the coefficients of the variables in the discriminant function shows that only moretime, reliable, sympathetic, and trustworthy contribute. Using only these variables the classification is that amongst those in the Shy group 10 are classified as shy and 2 as confident, and amongst those in the Confident group the classification remains unchanged. Moreover, using a predictive "leave-one-out" procedure where for each observation 23 data points are used to predict the remaining one, the rate of classification success becomes $67 \%$ (i.e., 8 out of 12 in each group are correctly predicted from the discriminant function).

\section{BEHAVIORAL RESPONSES - SECOND BELL TIME}

Participants had been asked to ring the bell after completing the questionnaire in order to call Jenny back after she had left to take the phone call. All participants rang the bell at least twice: the first time after they finished the questionnaire, and the second time when the Jenny character did not return. A critical variable was how long they would wait before ringing the bell a second time after the first bell ring, and whether this depended on the personality of both the virtual character and the participants themselves. We define the waiting time between the first and second bell ring as $\Delta T_{\text {bell }}$.

The means and standard errors of $\Delta T_{\text {bell }}$ are $39 \pm 7.3 \mathrm{~s}(n=12)$ for the Shy condition and $86 \pm 19.2 \mathrm{~s}$ for the Confident. A one way ANOVA of $\Delta T_{\text {bell }}$ on condition (Shy/Confident) reveals a significant difference between the means $(P=0.032$, with effect size $\left.\eta^{2}=0.19\right)$. However, the residual errors of the model are not
Table 3 | Proportion of "yes" responses by condition ( $n=12$ each group).

\begin{tabular}{lccc}
\hline Statement & Confident & Shy & $\boldsymbol{P}$ \\
\hline I liked the interviewee & 0.50 & 0.83 & 0.083 \\
I would like to spend more time with & 0.33 & 0.83 & 0.013 \\
the interviewee & & & \\
I feel the interviewee is reliable & 0.50 & 0.58 & 0.682 \\
| feel the interviewee is honest & 0.91 & 0.91 & - \\
| feel the interviewee is sociable & 0.17 & 0.17 & - \\
| feel the interviewee is friendly & 0.42 & 0.67 & 0.219 \\
| feel the interviewee is sympathetic & 0.33 & 0.67 & 0.102 \\
| feel the interviewee is trustworthy & 0.50 & 0.83 & 0.083 \\
Mean \pm SE number of "yes" answers & $3.7 \pm 0.59$ & $5.5 \pm 0.47$ & 0.024
\end{tabular}

$P$ is the two-tailed significance level for the test of differences of proportions between the two groups.

normally distributed according to a Shapiro-Wilk test $(P=0.004)$. A transformation to $\log \left(\Delta T_{\text {bell }}\right)$ eliminates this problem. Under the log transformation the ANOVA still reveals the difference between the means to be significant $\left(P=0.020, \eta^{2}=0.22\right)$ and the Shapiro-Wilk test shows that the distribution of the residual errors of the model is compatible with normality $(P=0.18)$. Hence it is clear that those who had experienced the "confident" virtual character waited significantly longer to ring the bell the second time compared to those who experienced the "shy" virtual character.

Amongst the NEO big-five factor personality variables there is a significant positive correlation between $\log \left(\Delta T_{\text {bell }}\right)$ and participants' level of Neuroticism $(r=0.49, P<0.013)$. An analysis of covariance of $\log \left(\Delta T_{\text {bell }}\right)$ on condition, and using Neuroticism as a covariate results in two parallel regression lines with a positive slope $\left(P=0.018\right.$, Partial $\left.\eta^{2}=0.24\right)$ and a significant difference between the intercepts $\left(P<0.027\right.$, Partial $\left.\eta^{2}=0.21\right)$, with the intercept greater for those exposed to the Confident virtual character. (The residual errors are compatible with normality, Shapiro-Wilk $P=0.36$ ). In other words on average for any given level of Neuroticism, those exposed to the Confident virtual character were more likely to wait longer to ring the bell the second time, and generally for each group the greater the level of Neuroticism the longer the waiting time before ringing the second bell. None of the other personality variables, nor the SAD scale, were correlated with $\log \left(\Delta T_{\text {bell }}\right)$.

\section{BEHAVIORAL RESPONSES - END TIME}

The experiment was terminated if participants took off the stereo glasses, or recalled the experimenter, or stood up. In any case it was stopped after $10 \mathrm{~min}$ of waiting time if the participant did not terminate it earlier. We denote the waiting time between the first bell ring and the termination time as $\Delta T_{\text {end }}$.

The mean and standard errors of $\Delta T_{\text {end }}$ are $314 \pm 52 \mathrm{~s}$ for those in the Confident and $292 \pm 43 \mathrm{~s}$ for those in Shy condition. A one way ANOVA of $\log \left(\Delta T_{\text {end }}\right)$ on Condition (shy/confident) shows no difference between the means $(P>0.7)$. No association was found with personalities or the score of the SAD questionnaire. 


\section{RELATIONSHIP BETWEEN BEHAVIORAL AND QUESTIONNAIRE RESPONSES}

Further evidence regarding the meaning of the waiting time variable $\log \left(\Delta T_{\text {bell }}\right)$ can be obtained by relating it to the subjective variables in Table 3. In order to examine this we carried out a stepwise regression of $\log \left(\Delta T_{\text {bell }}\right)$ on that set of variables, with inclusion significance level 0.01, and deletion level 0.05. Using forward stepwise regression the final model includes only the variable sympathetic. This has coefficient $-0.86(\mathrm{SE}=0.29$, $P=0.007$, partial $\eta^{2}=0.29$ ) indicating that the waiting time was less amongst those who were sympathetic to the virtual character. Using backwards stepwise regression the final model includes both sympathetic (coefficient $=-1.01, \mathrm{SE}=0.28, P=0.002$, partial $\eta^{2}=0.39$ ) and reliable (coefficient $=0.59, \mathrm{SE}=0.28, P=0.045$, partial $\eta^{2}=0.18$ ). This also makes sense since it indicates that participants were prepared to wait longer if they had evaluated the character as reliable (she said she would return so if she were reliable she probably would).

\section{PRESENCE QUESTIONNAIRE}

After the experiment, participants answered a further questionnaire concerned with presence - (Sanchez-Vives and Slater, 2005) and references therein. Presence has been argued to consist of two attributes: the sensation of being in the place depicted by the virtual environment (Place Illusion, PI), and Plausibility (Psi) the illusion that the events occurring there are real. Both are illusions may occur in spite of participants knowing for sure that these are illusions (Slater, 2009).

Place illusion depends on the mechanisms by which the participant is able to use their body for perception in the normal way (Slater, 2009). In other words, the more the system has affordances for perception through natural sensorimotor contingencies (O'Regan and Noë, 2001), the greater the chance for the illusion of being in the virtual place. Since in this experiment all participants were in the Cave, seeing a wide field-of-view in stereo with head-tracking enabled we would not expect any difference in reported presence between the two conditions. In the presence questionnaire there were five questions in relation to this where each question was rated on a scale of 1 (low presence) to 7 (high presence). The questionnaire has been used in many previous papers, for example, (Slater and Steed, 2000).

Table 4 shows that the median level of reported presence was at least equal to the mid-point of the Likert scale for each question (and below the mid-point for the reversed scale questions) and for the first two questions $50 \%$ of participants gave scores at least equal to 5. Moreover, it is clear that there is no difference in reported presence between the two conditions.

Psi is thought to depend on correlations between events in the environment and the actions of the participant, on whether there are events in the environment that are directed personally toward the participant, and the overall credibility of the environment in circumstances when it is supposed to be a simulation of real-life events. There were 10 questions related to the concept of Psi, the first five in relation to the situation, and the second 5 in relation to interactions with the virtual woman.

Table 5 shows the questionnaire scores for various aspects of Plausibility. All scores except one are at least equal to the mid-point
Table 4 | Median (and IQR) for place illusion (presence questionnaire).

\begin{tabular}{|c|c|c|}
\hline Question & Confident & Shy \\
\hline $\begin{array}{l}\text { Please rate your sense of being in the interview, on } \\
\text { the following scale from } 1 \text { to } 7 \text {, where } 7 \text { represents }\end{array}$ & $5.0(2.5)$ & $5.0(2$ \\
\hline
\end{tabular}

To what extent were there times during the $5.0(2.5) \quad 4.0(3.0)$ experience when the interview was the reality for you?

When you think back about your experience, do $4.0(2.0) \quad 4.0(3.5)$ you think of the interview more as images that you saw, or more as somewhere that you visited?

During the time of the experience, which was $3.5(2.0) \quad 3.0(2.5)$ strongest on the whole, your sense of being in the interview, or of being in the real world of the laboratory? ${ }^{a}$

During the time of the experience, did you often $3.5(2.5) \quad 3.5(2.5)$ think to yourself that you were just sitting in a laboratory or did the interview overwhelm you? ${ }^{a}$

Questions were on a 1-7 scale where 7 represented greater Pl, except for ${ }^{a}$ which was reverse coded.

of the Likert scale, and out of the 20 scores in both conditions 12 have medians of at least 5 . By inspection of the median scores and their interquartile ranges there is no difference in Psi between the Confident and Shy conditions.

These results are important since they show that any other differences found between the two conditions are not caused by differences in presence between the two situations.

\section{COMMENTS AND INTERVIEW}

Above we have presented the statistical results. However, after the experiment we asked the participants to write some openended comments about their experiences, and we also conducted an interview with them. This is valuable since it allows us to probe responses in more depth and may help to understand the quantitative results. Here, we report typical comments that give some insight into their responses during the interaction. We present participants' general comments, as well as their comments regarding some of the virtual character's personal traits.

\section{Personality type}

First, we consider the participant's views of the personality of the virtual character. This is a qualitative variable where we report the adjectives used to describe her. After interacting with the "shy" virtual character, 8 out of 12 participants spontaneously included words that directly related to shyness (half of them mentioned "shy" directly, the other half mentioned words such as "introverted," "embarrassed," "hesitating," and "anti-social”). The other four participants commented that she was: "all right," "artistic," "honest," or "hot and sexy," respectively. In contrast, in the case of the "confident" virtual character, 7 out of 12 participants used adjectives such as: open, rude, manipulative, unsympathetic, blunt, cold, direct, and straightforward. Amongst the other five, one said 
Table 5 | Median (and IQR) for plausibility (presence questionnaire)

\begin{tabular}{|c|c|c|}
\hline Question & Confident & Shy \\
\hline $\begin{array}{l}\text { How much did you behave within the interview as } \\
\text { if the situation were real? }\end{array}$ & $5.5(1.0)$ & $5.5(3.0)$ \\
\hline $\begin{array}{l}\text { How much was your emotional response in the } \\
\text { interview the same as if it had been real? }\end{array}$ & $5.0(0.5)$ & $5.5(1.5)$ \\
\hline $\begin{array}{l}\text { How much were the thoughts you had within the } \\
\text { interview the same as if it had been a real } \\
\text { situation? }\end{array}$ & $4.0(2.0)$ & $5.0(2.0)$ \\
\hline $\begin{array}{l}\text { How much were you thinking things like "I know } \\
\text { this isn't real" but then surprisingly finding yourself } \\
\text { behaving as if it was real? }\end{array}$ & 4.5 (3.0) & $5.5(2.0)$ \\
\hline $\begin{array}{l}\text { To what extent were your physical responses within } \\
\text { the interview (e.g., heart rate, blushing, sweating, } \\
\text { etc.) the same as if it had been a real situation? }\end{array}$ & $4.0(1.0)$ & $5.0(2.0)$ \\
\hline $\begin{array}{l}\text { How much did you behave as if the interviewee } \\
\text { were real? }\end{array}$ & $5.0(1.5)$ & $5.0(1.5)$ \\
\hline $\begin{array}{l}\text { How much was your emotional response to the } \\
\text { interviewee as if she were real? }\end{array}$ & $4.5(1.5)$ & $4.5(3.0)$ \\
\hline $\begin{array}{l}\text { How much were your thoughts in relation to the } \\
\text { interviewee as if she were real? }\end{array}$ & $4.0(2.5)$ & $5.0(3.0)$ \\
\hline $\begin{array}{l}\text { How much were you thinking things like "I know } \\
\text { this person isn't real" but then surprisingly finding } \\
\text { yourself behaving as if he/she was real? }\end{array}$ & $5.0(2.0)$ & $5.0(2.5)$ \\
\hline $\begin{array}{l}\text { How much did you have physical responses (such } \\
\text { as change in heart rate, blushing, sweating, etc.) to } \\
\text { the interviewee as if she were real? }\end{array}$ & $3.5(2.5)$ & $3.5(3.0)$ \\
\hline
\end{tabular}

Questions were on a 1-7 scale where 7 represented greater Psi.

she was negative, one said she was "a quiet girl", the other three said they felt there was a conflict in her personality.

\section{General comments}

The following illustrate how the confident virtual character could make the participant uncomfortable:

Certainly she was very horrible looking, and when she leaned forward over the laptop screen, or extended her hand toward me, I recoiled. At the same time she had a sexual allure. (Confident Condition).

I could sense by the answers she was giving that she was uncomfortable with the situation and wasn't relaxed. This made the whole scenario feel even more lifelike and made me feel uncomfortable as well. (Confident Condition).

The following comments from participants are further examples indicating that they felt the experience was real:

When she first walked past me I had a sort of mental shiver a very weird surreal feeling as if I was next to an alien or something, but that quickly passed. Otherwise the whole experience was very real, and I was surprised at my emotional response to the character. (Shy Condition).

The experience felt real because the body language of the interviewee was realistic and in turn my body language responded. (Confident Condition).

\section{Would they like to spend more time with Jenny?}

In the questionnaire 10 out of 12 participants said they would like to spend more time with the Shy virtual character (Table 3). However in the interview, only six of them said that they actually wanted to spend more time with her, and two were neutral about this question. Four participants said that they would not like to spend more time with her, because, for example,

She's not very happy is she? Obviously, like, again, I feel weird now. Cause I'm talking as if she was a real person. In that situation she was obviously uncomfortable, because she was not very sociable. (Shy Condition).

After interacting with the Confident virtual character 8 out of 12 answered in the questionnaire that they would not like to spend more time with the character (Table 2). The same pattern was maintained in the interview: all of these eight participants said, without hesitation, which they would not like to spend more time with her, because she "makes me feel uncomfortable as I was asking her these questions," and "She seemed a bit aggressive." However, the other four participants said they felt curious about the virtual character and would like to find out more about her. One participant commented: "I would be interested in sort of continuing that interview. I'm not sure if she would remain like that. She's obviously some kind of awkward. But I think she would probably improve once she's gotten to know someone."

For those in the Confident condition the interview responses were consistent with the questionnaire. However in the Shy condition, it is interesting to notice that there were fewer participants who said they would like to spend more time in the post-experimental interview than on the questionnaire. Recall that when they answered that questionnaire they believed that it would be reviewed together with Jenny, and perhaps they were more reluctant to write down more negative responses.

\section{Is Jenny honest and reliable?}

Overall Table 3 suggests that participants who experienced the Shy character had a more favorable view of her than those who experienced the Confident one. However, the answer to whether the character was "honest" had identical ratings (11/12 said "yes," Table 3 ) and the ratings were similar between the two conditions with respect to reliable (6 and 7 out of 12).

After interacting with the Shy virtual character, some participants thought she might not be reliable or trustworthy because of her shyness. One commented: "From her answers to the questions she was very anti-social. Anti-social people tend to be less reliable."

Another participant who did not think that Shy Jenny was reliable explained: "She's the type of person that I think just has a lot of difficulties in her life. It can create a lot of emotional disturbance. And I think most of the disturbance can kind of make a person behave differently from how maybe they would normally behave if they were happier. So it might make her do things that she doesn't want to do." 
With the Confident virtual character, several participants thought she was honest, because, for example, "A lot of the questions she gave I felt were her honest opinion," "She was genuinely giving answers that weren't easy answers to give," "She was very direct about things," "I didn't see any hints of a lying personality."

However, there was one participant who thought she was not honest because "Her body language conflicted with her answers."

\section{DISCUSSION}

The importance of including personality in the design of virtual characters is that it may increase the believability of the character and thereby result in a more appealing and engaging interaction for participants (Loyall and Bates, 1997; Isbister and Nass, 2000). Moreover understanding the personality of a character allows the participant to predict-ahead likely behavior and, as a result, enhances the plausibility of the experience.

There is significant work on how to generate speech based on personality, for example, the improvisation method discussed in Walker et al. (1997). There have also been experimental studies in this domain of linguistic style and personality. For example, Rushforth et al. (2009) reports two experiments comparing dialog personality models over a number of factors. Subjects interacted with a virtual character displayed on a screen, and in one experiment it was shown as a static image and in the other there was speech and animation. Critically the purpose of the experiments was to test whether participants recognized different aspects of the personality expressed through the linguistic style (for example, the degree of assertiveness). On similar lines Krishnan et al. (2012) was concerned with whether subjects would recognize two different types of dialog style - high or low verbosity. In each of these studies the measures were questionnaire scores with no behavioral measures. They were not concerned with how people would respond behaviorally to the different dialog styles but rather whether they would recognize them. These are somewhat like our online study reported in Section "Validation of the Representation of Personality through an Online Study" where we asked respondents to evaluate online two different personalities.

Other approaches focus on non-verbal cues, for example, facial expression and body movements. Facial expression has been closely studied as the expression of emotion. However, when it comes to personality, the body provides a critical additional expressive cue (for example, distinguishing an "extraverted gesture/posture" and an "introverted gesture/posture"). Although facial expressions may serve as conscious communicative acts and are often deliberately delivered (Bavelas and Chovil, 1997; Pelachaud and Bilvi, 2003), body movements are more often the "emotional leakage" that reveals the personality of a person (Argyle, 1988; Knapp and Hall, 2009).

Several studies of personality expressed through body movement have focused on communicative body movements such as gesture (Neff et al., 2008) and posture (Isbister and Nass, 2000); others have focused on locomotion, such as walking style (McDonnell et al., 2007). In the study by Isbister and Nass (2000), virtual agents with extroverted or introverted characteristics in their posture and linguistic style (text displays) were presented to participants. The results suggested that virtual agents that had shown a consistent posture and linguistic style (e.g., extroverted posture with extroverted linguistic style) were preferred over the inconsistent ones (e.g., introverted posture with extroverted linguistic style), with the consistent characters being rated higher in both liking and persuasiveness. Moreover, they also pointed out that participants preferred a character with a complementary personality rather than with one similar one to themselves, although contradicting previous findings (Rosis et al., 2003).

In our study, we have focused on the body and voice, while holding facial expression constant. It is notable that none of the participants mentioned the unchanging facial expression nor the lack of lip sync. We had found the same in an earlier experiment (Slater et al., 2013) where participants were bystanders to a violent confrontation between two virtual characters. In a post-experiment questionnaire participants had been asked to list factors that drew them out of the experience. Only 5 out of 40 participants mentioned the lack of lip sync as such a factor, and it was only 5 th in the list of mentioned items. This experiment was also carried out in a Cave. Looking at a video of the scenario on a 2D display, the lack of lip sync is obvious and glaring. However, in the Cave, with the illusion of presence, and the ongoing narrative participants may become engaged in the action, in the body movement and verbal exchanges, and simply not notice obvious faults in the scenario. This is would be an interesting hypothesis to test in further studies.

Our most noteworthy result is that participants in the Confident condition waited on the average much longer before ringing the bell compared with those in the Shy condition. This is probably because participants in that condition were more anxious about her reaction on being recalled, and therefore less eager for her to return. This is borne out by the further finding of a differential relationship between the waiting time between the first and second bell and the degree of neuroticism. For both groups the waiting time increased with neuroticism, but it was generally higher for those in the Confident condition. It is known that neuroticism is positively correlated with anxiety in the NEO classification - for example (Costa and McCrae, 1992) - so that the general increase in waiting time with neuroticism does point to the possibility that anxiety was a factor in this. Moreover, interacting with a character that tended to make the participants uncomfortable would be more likely to generate such anxiety.

Typically research into the effects of personality on interactions between virtual and human characters has taken place in online virtual worlds (Yee et al., 2011), and desktop based interactive games (Isbister and Nass, 2000). In contrast in our study participants interacted with a life-sized virtual character in an immersive virtual environment where reality was substituted by the virtually generated stimuli. Furthermore, our design allowed us to trigger responses for the virtual character quickly, and with some of the verbal responses relating personally to the participants themselves. Our technique of asking the participants to administer a verbal questionnaire to the virtual character gave rise to quite realistic verbal interactions without the need for any method of speech recognition or generation. This type of paradigm could be used in future research that investigates the impact of virtual character behavior and on participants. 
A fundamental contribution of this work is that we used an immersive system to assess the effects of virtual character personality on the behavior of participants in an immersive system. The importance of this is that an immersive system does not just refer to the type of display but critically the ability of participants to react in a normal way using their body to move and talk, as if they were having a conversation with a real person, sitting in front of them, life sized in the same (virtual) space. Therefore we argue that our findings have greater ecological validity than other studies where people interact with characters displayed on a screen and even use a keyboard and chat window. Second, as we showed in Section "Relationship between Behavioral and Questionnaire Responses" there is a relationship between our behavioral measure and some of the evaluative questionnaire responses. These points to the internal validity of our setup - where the behaviors of the participants were to some extent consistent with their subjective evaluations. In this paper we provide evidence that the virtual character's non-verbal behavior had a significant impact in an ecologically valid setting where participant could act as they normally would in reality.

One limitation of the study was that it was restricted to males only interacting with a virtual female, and only two personality types. We would not expect any fundamentally different conclusions with female participants, or same gender interactions, but these are empirical questions open to further study. Moreover, it would be interesting to know whether more subtle differences in personality would also trigger different participant responses. Another limitation is that we used the combination of body movement and the tone of voice to represent the personality of the virtual character. It would be useful in further studies to disambiguate the effect of these two factors.

As the visual and behavioral realism of virtual characters increases, the complexity of human-virtual character interaction will correspondingly increase. In future, experimental designs more intense effort will be needed to incorporate knowledge from psychology and social neuroscience regarding interpersonal communications. It is likely that eventually human-virtual character social interaction will become indistinguishable from human-human interaction.

\section{ACKNOWLEDGMENTS}

We would like to thank Dr. David Swapp for help with setting up the equipment. We thank Gemma Salter for the motion capture in the role of the Jenny. We would also like to thank Prof. Chris Barker and Dr. Peter Scragg for their advice on the choice of questionnaire for the evaluation of personality. This work was supported by EPSRC grant Empathic Virtual character EP/D505542/1 and Visual and Behavioral Fidelity of Virtual Humans EP/F030355/1, and Mel Slater's Advanced ERC Grant TRAVERSE (\#227985).

\section{SUPPLEMENTARY MATERIAL}

The Supplementary Material for this article can be found online at http://www.frontiersin.org/Journal/10.3389/frobt.2015.00001/ abstract

Video S1 | An interaction with the virtual character in the Shy condition The video was filmed from outside the Cave and therefore since the Cave display is stereo the images look blurred.
Video S2 | An interaction with the virtual character in the Confident condition. The video was filmed from outside the Cave and therefore since the Cave display is stereo the images look blurred.

\section{REFERENCES}

Anderson, P., Rothbaum, B. O., and Hodges, L. F. (2003). Virtual reality exposure in the treatment of social anxiety. Cogn. Behav. Pract. 10, 240-247. doi:10.1016/S1077-7229(03)80036-6

Argyle, M. (1988). Bodily Communication, 2nd Edn, Routledge, London.

Asendorpf, J. B. (1990). "The expression of shyness and embarrassment," in Shyness and Embarrassment: Perspectives from Social Psychology, ed. W. R. Crozier (New York, NY: Cambridge University Press), 87-118.

Bailenson, J. N., Blascovich, J., Beall, A. C., and Loomis, J. (2003). Interpersonal distance in immersive virtual environments. Pers. Soc. Psychol. Bull. 29, 1-15. doi:10.1177/0146167203029007002

Bailenson, J. N., Swinth, K., Hoyt, C., Persky, S., Dimov, A., and Blascovich, J. (2005). The independent and interactive effects of embodied-agent appearance and behavior on self-report, cognitive, and behavioral markers of copresence in immersive virtual environments. Presence (Camb) 14, 379-393. doi:10.1162/105474605774785235

Bavelas, J. B., and Chovil, N. (1997). "Faces in dialogue," in The Psychology of Facial Expression. Studies in emotion and social interaction, 2nd series, eds J. A. Russell and J. M. Fernández-Dols (New York, NY: Cambridge University Press), 334346; Paris, France: Editions de la Maison des Sciences de l'Homme, xiii, 400. doi:10.1017/CBO9780511659911.017

Blascovich, J. (2002). Social Influence within Immersive Virtual Environments. London: Springer CSCW Series, 127-145.

Blascovich, J., Loomis, J., Beall, A. C., Swinth, K., Hoyt, C., and Bailenson, J. N. (2002). Immersive virtual environment technology as a methodological tool for social psychology. Psychol. Inq. 13, 103-124. doi:10.1207/S15327965PLI1302_01

Coll, C. G., Kagan, J., and Reznick, J. S. (1984). Behavioral inhibition in young children. Child Dev. 55, 1005-1019. doi:10.2307/1130152

Connelly, B. S., and Ones, D. S. (2010). An other perspective on personality: metaanalytic integration of observers' accuracy and predictive validity. Psychol. Bull. 136, 1092. doi:10.1037/a0021212

Costa, P. T., and McCrae, R. R. (1992). Normal personality assessment in clinical practice: the NEO personality inventory. Psychol. Assess. 4, 5. doi:10.1037/10403590.4.1.20

Cruz-Neira, C., Sandin, D. J., Defanti, T. A., Kenyon, R. V., and Hart, J. C. (1992). The CAVE: audio visual experience automatic virtual environment. Commun. ACM 35, 64-72. doi:10.1145/129888.129892

Cukor, J., Spitalnick, J., Difede, J. A., Rizzo, A., and Rothbaum, B. O. (2009). Emerging treatments for PTSD. Clin. Psychol. Rev. 29, 715-726. doi:10.1016/j.cpr.2009. 09.001

Edelmann, R. J., and Hampson, S. E. (1981). Embarrassment in dyadic interaction. Soc. Behav. Personal. 9, 171-177. doi:10.2224/sbp.1981.9.2.171

Emmelkamp, P. M., Krijn, M., Hulsbosch, A. M., de Vries S, Schuemie, M. J., and van der Mast, C. A. P. G. (2002). Virtual reality treatment versus exposure in vivo: a comparative evaluation in acrophobia. Behav. Res. Ther. 40, 509-516. doi:10.1016/S0005-7967(01)00023-7

Garau, M., Slater, M., Pertaub, D.-P., and Razzaque, S. (2005). The responses of people to virtual humans in an immersive virtual environment. Presence (Camb) 14, 104-116. doi:10.1089/cpb.2009.0192

Garau, M., Slater, M., Vinayagamoorthy, V., Brogni, A., Steed, A., and Sasse, A. M. (2003). "The impact of avatar realism and eye gaze control on the perceived quality of communication in a shared immersive virtual environment," in Proceedings of the SIGCHI Conference on Human Factors in Computing Systems CHI '03 (New York, NY: ACM), 529-536. doi:10.1145/642611.642703

Gillath, O., Mccall, C., Shaver, P. R., and Blascovich, J. (2008). What can virtual reality teach us about prosocial tendencies in real and virtual environments? Media Psychol. 11, 259-282. doi:10.1080/15213260801906489

Gillies, M., and Spanlang, B. (2010). Comparing and evaluating real-time character engines for virtual environments. Presence (Camb) 19, 95-117. doi:10.1162/pres. 19.2.95

Henderson, L., Zimbardo, P., and Carducci, B. (2010). "Shyness," in Corsini Encyclopedia of Psychology, Vol. 4. Hoboken: John Wiley, p1592.

Hodges, L. F., Anderson, P., Burdea, G. C., Hoffman, H. G., and Rothbaum, B. O. (2001). Treating psychological and physical disorders with VR. Ieee Comput. Graph. Appl. 21, 25-33. doi:10.1109/38.963458 
Isbister, K., and Nass, C. (2000). Consistency of personality in interactive characters: verbal cues, non-verbal cues, and user characteristics. Int. J. Hum. Comput. Stud. 53, 251-267. doi:10.1006/ijhc.2000.0368

Kastanis, I., and Slater, M. (2012). Reinforcement learning utilizes proxemics: an avatar learns to manipulate the position of people in immersive virtual reality. ACM Trans. Appl. Percept. 9:3. doi:10.1145/2134203.2134206

Keltner, D., and Buswell, B. N. (1997). Embarrassment: its distinct form and appeasement functions. Psychol. Bull. 122, 250. doi:10.1037/0033-2909.122.3.250

Knapp, M. L., and Hall, J. A. (2009). Nonverbal Communication in Human Interaction. Boston, MA: Wadsworth Pub Co.

Krijn, M., Emmelkamp, P. M. G., Olafsson, R. P., and Biemond, R. (2004). Virtual reality exposure therapy of anxiety disorders: a review. Clin Psychol Rev 24, 259-281. doi:10.1016/j.cpr.2004.04.001

Krishnan, V., Foster, A., Kopper, R., and Lok, B. (2012). "Virtual human personality masks: a human computation approach to modeling verbal personalities in virtual humans," in Intelligent Virtual Agents (Berlin: Springer), 146-152.

Leary, M. R. (1983). Social anxiousness: the construct and its measurement. J. Pers. Assess. 47, 66-75. doi:10.1207/s15327752jpa4701_8

Lee, S. P., Badler, J. B., and Badler, N. I. (2002). "Eyes alive," in ACM Transactions on Graphics (TOG) (ACM), 21, 637-644.

Llobera, J., Spanlang, B., Ruffini, G., and Slater, M. (2010). Proxemics with multiple dynamic characters in an immersive virtual environment. ACM Trans. Appl. Percept. 8, 3. doi:10.1145/1857893.1857896

Loomis, J. M., Blascovich, J. J., and Beall, A. C. (1999). Immersive virtual environment technology as a basic research tool in psychology. Behav. Res. Methods Instrum. Comput. 31, 557-564. doi:10.3758/BF03200735

Loyall, A. B., and Bates, J. (1997). "Personality-rich believable agents that use language," in Proceedings of the First International Conference on Autonomous Agents. (ACM), 106-113

Maatman, R., Gratch, J., and Marsella, S. (2005). "Natural behavior of a listening agent," in Intelligent Virtual Agents (Berlin: Springer), 25-36.

McCall, C., Blascovich, J., Young, A., and Persky, S. (2009). Proxemic behaviors as predictors of aggression towards black (but not white) males in an immersive virtual environment. Soc. Influence 4, 138-154. doi:10.1080/15534510802517418

McCrae, R. R., and Costa, P. T. Jr. (1999). A five-factor theory of personality. Handb. Pers. Theory Res. 2, 139-153.

McDonnell, R., Jörg, S., Hodgins, J. K., Newell, F., and O’sullivan, C. (2007). "Virtual shapers \& movers: form and motion affect sex perception," in Proceedings of the 4th Symposium on Applied Perception in Graphics and Visualization. (ACM), 7-10.

Milgram, S. (1974). Obedience to Authority. New York: Harper and Row.

Neff, M., Kipp, M., Albrecht, I., and Seidel, H. P. (2008). Gesture modeling and animation based on a probabilistic re-creation of speaker style. ACM Trans. Graph. 27, 5. doi:10.1145/1330511.1330516

O'Regan, J. K., and Noë, A. (2001). A sensorimotor account of vision and visual consciousness. Behav. Brain Sci. 24, 939-1031. doi:10.1017/S0140525X01000115

Pan, X., Gillies, M., Barker, C., Clark, D. M., and Slater, M. (2012). Socially anxious and confident men interact with a forward virtual woman: an experimental study. PLoS ONE 7:e32931. doi:10.1371/journal.pone.0032931

Pan, X., Gillies, M., and Slater, M. (2008). "Male bodily responses during an interaction with a virtual woman," in Intelligent Virtual Agents (Berlin: Springer-Verlag), 89-96.

Paul, G. L. (1966). Insight vs. Desensitization in Psychotherapy: An Experiment in Anxiety Reduction. Palo Alto, CA: Stanford Univ Pr.

Pelachaud, C., and Bilvi, M. (2003). Computational model of believable conversational agents. Commun. Multiagent Syst. 2650, 300-317. doi:10.1007/978-3-54044972-0_17

Pertaub, D.-P., Slater, M., and Barker, C. (2002). An experiment on public speaking anxiety in response to three different types of virtual audience. Presence (Camb) 11, 68-78. doi:10.1162/105474602317343668

Rizzo, A., and Kim, G. J. (2005). A SWOT analysis of the field of virtual reality rehabilitation and therapy. Presence (Camb) 14, 119-146. doi:10.1162/ 1054746053967094

Rosis, F., Pelachaud, C., Poggi, I., Carofiglio, V., and Carolis, B. D. (2003). From Greta's mind to her face: modelling the dynamics of affective states in a conversational embodied agent. Int. J. Hum. Comput. Stud. 59, 81-118. doi:10.1016/ S1071-5819(03)00020-X
Rovira, A., Swapp, D., Spanlang, B., and Slater, M. (2009). The use of virtual reality in the study of people's responses to violent incidents. Behav. Neurosci. 3, 1-10. doi:10.3389/neuro.08.059.2009

Rushforth, M., Gandhe, S., Artstein, R., Roque, A., Ali, S., Whitman, N., et al. (2009). "Varying personality in spoken dialogue with a virtual human," in Intelligent Virtual Agents (Berlin: Springer), 541-542.

Sanchez-Vives, M. V., and Slater, M. (2005). From presence to consciousness through virtual reality. Nat. Rev. Neurosci. 6, 332-339. doi:10.1038/nrn1651

Slater, M. (2009). Place illusion and plausibility can lead to realistic behaviour in immersive virtual environments. Philos. Trans. R. Soc. Lond. B Biol. Sci. 364, 3549-3557. doi:10.1098/rstb.2009.0138

Slater, M., Antley, A., Davison, A., Swapp, D., Guger, C., Barker, C., et al. (2006). A virtual reprise of the Stanley milgram obedience experiments. PLoS One 1:e39. doi:10.1371/journal.pone.0000039

Slater, M., Rovira, A., Southern, R., Swapp, D., Zhang, J. J., Campbell, C., et al. (2013). Bystander responses to a violent incident in an immersive virtual environment. PLoS One 8:e527660. doi:10.1371/journal.pone.0052766

Slater, M., and Steed, A. (2000). A virtual presence counter. Presence (Camb) 9, 413-434. doi:10.1162/105474600566925

Snyder, M. (1974). Self-monitoring of expressive behavior. J. Pers. Soc. Psychol. 30, 526. doi:10.1037/h0037039

Tecchia, F., Carrozzino, M., Bacinelli, S., Rossi, F., Vercelli, D., Marino, G., et al. (2010). A flexible framework for wide-spectrum VR development. Presence: Teleoper. Virtual Environ. 19, 302-312. doi:10.1162/PRES_a_00002

Vinayagamoorthy, V., Garau, M., Steed, A., and Slater, M. (2004). An eye gaze model for dyadic interaction in an immersive virtual environment: practice and experience. Comput. Graph. Forum 23, 1-11. doi:10.1111/j.1467-8659.2004. 00001.x

Vinayagamoorthy, V., Gillies, M., Steed, A., Tanguy, E., Pan, X., Loscos, C., et al. (2006). "Building expression into virtual characters," in Eurographics Conference State of the Art Report, Vienna.

Vinayagamoorthy, V., Steed, A., and Slater, M. (2008). The impact of a character posture model on the communication of affect in an immersive virtual environment. Computer 14, 1-17. doi:10.1109/TVCG.2008.62

Walker, M. A., Cahn, J. E., and Whittaker, S. J. (1997). "Improvising linguistic style: social and affective bases for agent personality," in Proceedings of the First International Conference on Autonomous Agents, (ACM), 96-105.

Watson, D., and Friend, R. (1969). Measurement of social-evaluative anxiety. J. Consult. Clin. Psychol. 33, 448-457. doi:10.1037/h0027806

Woods, S. A., and Hampson, S. E. (2005). Measuring the big five with single items using a bipolar response scale. Eur. J. Pers. 19, 373-390. doi:10.1002/per.542

Yee, N., Harris, H., Jabon, M., and Bailenson, J. N. (2011). The expression of personality in virtual worlds. Soc. Psychol. Pers. Sci. 2, 5-12. doi:10.1177/ 1948550610379056

Zanbaka, C. A., Ulinski, A. C., Goolkasian, P., and Hodges, L. F. (2007). "Social responses to virtual humans: implications for future interface design," in Proceedings of the SIGCHI Conference on Human Factors in Computing Systems (ACM), 1561-1570.

Conflict of Interest Statement: The authors declare that the research was conducted in the absence of any commercial or financial relationships that could be construed as a potential conflict of interest.

Received: 02 September 2014; accepted: 27 January 2015; published online: 10 February 2015.

Citation: Pan X, Gillies M and Slater M (2015) Virtual character personality influences participant attitudes and behavior - an interview with a virtual human character about her social anxiety. Front. Robot. AI 2:1. doi: 10.3389/frobt.2015.00001

This article was submitted to Virtual Environments, a section of the journal Frontiers in Robotics and AI.

Copyright (C) 2015 Pan, Gillies and Slater. This is an open-access article distributed under the terms of the Creative Commons Attribution License (CC BY). The use, distribution or reproduction in other forums is permitted, provided the original author(s) or licensor are credited and that the original publication in this journal is cited, in accordance with accepted academic practice. No use, distribution or reproduction is permitted which does not comply with these terms. 